\title{
The Evaluation of Process Parameters on Springback in V-bending Using the Flexforming Process
}

\author{
İbrahim Karaağaç ${ }^{a *}$ \\ ${ }^{a}$ Department of Manufacturing Engineering, Gazi University, 06500, Teknikokullar, Ankara, Turkey
}

Received: October 26, 2016; Revised: May 29, 2017; Accepted: July 03, 2017

\begin{abstract}
One of the most significant problems in bending sheet metals is the springback behavior caused by the elastic stress formed after the bending process. In this study, the effects of forming pressure, die angle and holding time on the springback behavior were experimentally investigated for V-bending using the flexforming process. Furthermore, springback behavior was predicted using a fuzzy logic system based on unexecuted break-test parameters. The study was carried out using a thin rubber membrane instead of the thick ones normally used in flexforming processes. During the flexforming process, it was observed that springback were $60.57 \%$ and $41.92 \%$ less than those formed by a conventional die for AL1050-0 and AL5754-0 sheet metal materials, respectively. It was determined that an increase of 15 degree in the die angle increased springback values on average by 0.12 degree and 0.23 degree for AL1050-0 and AL5754-0, respectively. It was also found that an increase of 10 seconds in the holding time decreased springback values on average by 0.14 degree and 0.19 degree for AL1050-0 and AL5754-0, respectively. It was determined that there were no forming defects on the surfaces of the parts bent through the flexforming process.
\end{abstract}

Keywords: Flexforming, Springback, V bending, Hydroforming

\section{Introduction}

The flexforming process is a sheet metal-forming method in which a sheet material is formed on a single fixed die by fluid pressure. This method is extensively used to form a large variety of sheet metal parts and parts manufactured in low volumes. Sheet metal parts formed in this way are used especially in aerospace, automotive and home appliances sectors for producing prototypes and a variety of parts with complex geometries. The flexforming process has become prominent due to its advantages of lower die costs - by using only half of the die - easy modification of the dies after changes allowing fast try-outs, and production of highquality parts with less damage to the sheet - less wrinkling and tearing - than conventional stamping ${ }^{1}$. Moreover, the process has some capability to form several parts with varied and complex geometries in a single operation, forms complex geometric parts by high-pressure and produce high quality parts with tight-tolerances.

Forming materials by bending is often used in both flexforming and other sheet metal-forming processes. However, sheet metal materials retain residual stresses after the bending process. These residual stresses cause springback. Springback is inevitable in a cold-forming process, and it is characterized by the tendency of materials subjected to a cold-forming process to return to the initial state after unloading ${ }^{2}$. Some material factors affect springback, such as initial anisotropy resulting from sheet rolling conditions and work hardening ${ }^{3}$, as well as process parameters, such as lubrication condition, blank holding force, thickness, die shape and blank size ${ }^{4}$. Usually, corrections to compensate for springback are made by modifying the shape of the stamping tools $\mathrm{s}^{5}$. Accurate estimation of springback is a very important step that needs to be taken into account during the design stage of the die. This is because, for the compensation of springback after die production, the correction of the geometry or determination of the ideal bending parameters by trial-and-error is time-consuming and costly.

Studies conducted on springback for V-bending using the flexforming process, and other sheet metal forming studies using the flexforming process in published literature are limited. In a study investigating springback for bending with the flexforming process, Kulkarni and Prabhakar investigated the effect of strain rates on springback in AL2024-0 and AL2024-T3 materials, and the springback of aluminum at different temperatures, using experimental and finite element analyses. They aimed to develop a predictive finite element technique for springback by using experimental verification. They determined that the springback predicted from simulations 
of AL2024-0 and AL2024-T3 materials were consistent with experimental results ${ }^{6}$. In another experimental study investigating springback using the flexforming process, Palaniswamy et al. examined the optimization of unformed sheet metal dimensions in conical parts to decrease springback. They aimed to decrease and predict the springback in axisymmetric parts formed using the flexforming process. They determined that optimization techniques can be used to decrease springback in unformed sheet metal dimensions using the finite element method. Finite element analyses are also used to simulate the flexforming process and predict defects ${ }^{7}$. The study carried out by Hatipoğlu et al. determined that the effects of the rolling direction and flange length on springback are insignificant, while the die radius and sheet metal thickness have a considerable effect on springback in the bending of AL2024-T3 sheet metal material ${ }^{1}$. In another study by Hatipoğlu et al. using the flexforming process, they aimed to determine the friction coefficient between the unformed sheet metal and the die surface in AL2024-0 sheet metal material through experimental and finite element analyses. They carried out experimental works under three friction conditions (dry, oiled and oiled with nylon) and under three pressure values. In addition, numerical forming analyses were done for different friction coefficients and pressure values. Friction coefficients corresponding to different friction conditions were determined by using matching results between experimental and numerical studies ${ }^{8}$.

Aluminum 1050 sheet metals are commonly used for the production of chemistry - food and industry equipment, household appliances, reflectors, in marine vehicles and in architectural applications. Aluminum 5754 sheet metals, on the other hand, are used for the production of welded structures used in chemistry - the food and nuclear industry, pressure vessels and boilers, in ship-building materials and in the automotive industry, as well as architectural applications. The elimination of forming defects occurring in the products of bending dies is time-consuming and costly, especially for those applications that include prototypes or where very limited production numbers are required. In this type of forming application, producing only one half of the die and forming several products simultaneously over one cycle is an important advantage of the flexforming process. However, springback is a big problem in forming of materials by flexforming. In addition, rubber materials having a thickness of at least $40 \mathrm{~mm}$ are used as membranes to resist the high hydraulic pressures encountered in the flexforming processes. Forming small or narrow profiles by using rubber is difficult; thus, hydraulic pressures at a minimum of $80 \mathrm{MPa}$ are necessary to form such profiles. Obtaining very high hydraulic pressures in the flexforming processes and operation them in a controlled and reliable manner requires high-energy consumption, expensive hydraulic equipment and special fabrication processes. In addition to, because thick rubber materials cannot fit into small or narrow geometries, commonly the male parts of the dies are produced by $\mathrm{V}$-bending in the flexforming process and forming is performed by the male dies. This situation limits to the die designer in the design phase of the bending die and the forming process. To stabilize the sheet material on the male part of the die during V-bending, it is fixed on the die by a connector, which increases the duration of the cycle time. This study aims to experimentally investigate the formability of aluminum sheet metal materials using a $4 \mathrm{~mm}$-thick rubber membrane and only the female part of the die through $\mathrm{V}$-bending using the flexforming process. Initially, experimental studies were conducted using a $4 \mathrm{~mm}$ thick rubber membrane and producing only the female part of the die. Later, the aim was to make a comparison using the springback angle occurring after forming AL 1050-0 and AL 5754-0 sheet metal materials using the flexforming method in a V-bending die with the conventional bending process. Experimental study was performed using the same test parameters in both flexforming and conventional bending processes to make this comparison.

\section{Experimental}

\subsection{Flexforming process and experimental study environment}

The flexforming process is a sheet metal forming method that uses hydraulic fluid pressure and a rubber diaphragm to form sheet metal with a die ${ }^{9}$. The diaphragm used in the flexforming process - a type of hydroforming process - is used to transfer hydraulic pressure to the sheet metal material to be formed, which enables hydraulic fluid to be used as a forming tool. The diaphragm also provides sealing and prevents the liquid diffusing into the working environment, which in turn enables a clean working environment. The operational sequence for the process is given in Figure $1^{7}$. The first step is to place the unshaped sheet metal on the die. In the second step, the press support provides a seal by closing on the die. In the third step, the sheet metal material is formed by pressurizing the hydraulic fluid. In the final step, the hydraulic fluid pressure is set to zero, and the process is completed by raising the press.

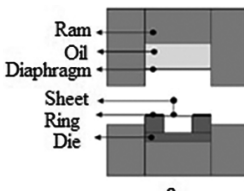

a

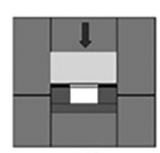

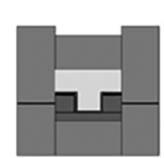

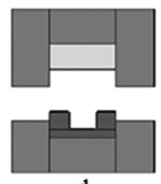

d
Figure 1. Flexforming process operation sequence a) Setup b) Shutdown c) Forming d) Opening

The experimental setup was prepared to ensure that it could carry out both flexforming and conventional bending processes in a computer-controlled manner. It consists of a 
mechanical construction, a hydraulic unit and valve group, an electronic control and data collection unit, and control software. The detailed view of die group and general view of the experimental study environment are shown in Figure 2.

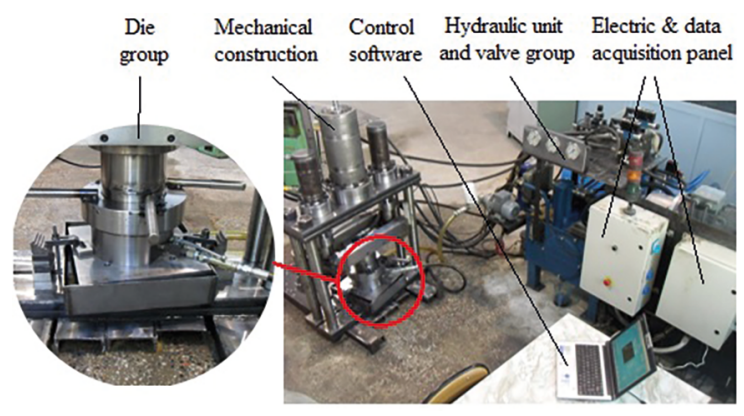

Figure 2. General and detailed views of the experimental study environment

In the first-stage design of the experimental setup, the mechanical group and die group were designed using 3D computer-aided design software. With the completion of the design stage, the mechanical parts were manufactured and assembled. The die group includes a lower fixture, a V-bending die, a conical part, an upper locking ring and an holding plate. The conical part was designed to be in direct contact with the rubber membrane on the sheet metal material placed on the die and to apply hydraulic fluid pressure to the sheet metal. The detailed views of the die group, with and without the membrane, are shown in Figure 3. In the system design, the bending operation of the flexforming process is performed in five steps. For the first step, the sheet metal material is placed on the die, and then the rubber membrane is placed on the sheet metal material. For the second step, the holding plate applies a pressure to the lower fixture part and the membrane by moving downwards. For the third step, the seal is provided by manually locking the system with the locking ring. For the fourth step, the hydraulic system performs the forming process by applying a pressure. In the last step, the locking ring is manually opened and the process is completed by moving the system upwards.

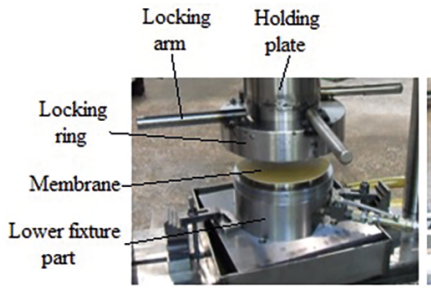

a

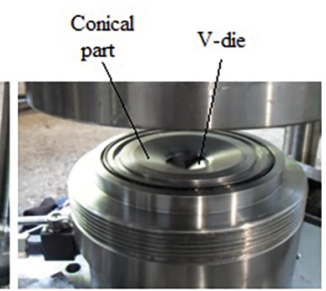

$\mathrm{b}$
Figure 3. The detailed views of die group a) with membrane, b) without membrane

The electronic control of the experimental setup uses Labview software especially designed for bending processes.
The data is obtained from the pressure sensor and load cell with an instantaneous read-data operation, which can be monitored and recorded in a text file. The data, including the forming pressure and holding time of the flexforming process, as well as the holding pressure and time in the conventional bending process are manually entered into the program.

For experimental studies, V-bending dies and punches were manufactured at angles of 15, 30, 45, 60, 75 and 90 degree. Dies were prepared by being cut on a wire erosion bench. V-bending dies were used for bending using the flexforming process, while V-bending dies and punches were used in the conventional bending process. The image of manufactured V-bending dies and punches are shown in Figure 4.

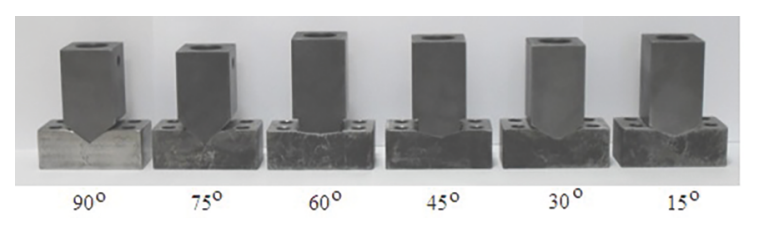

Figure 4. Manufactured V-bending dies and punches

\subsection{The characterization of test materials}

Aluminum has drawn attention from researchers due to its low cost and high corrosion resistance. AluminumMagnesium alloys including the 5XXX series have become prominent because of their high strength/weight ratios and excellent corrosion resistance properties. The springback problem is commonly observed in aluminum alloys because of their forming abilities at room temperature (RT) and their elastic modulus values are lower in comparison to steels. Since products manufactured by forming from AL 1050-0 and AL 5754-0 sheet metals have extensive uses in various sectors, they were selected as the test materials to be used. Before the experimental study, the mechanical and chemical properties of the test materials were determined. For the mechanical properties, tensile and Vickers hardness measurement tests were carried out, while chemical properties were determined by a spectrometer. For the tensile test, test samples were prepared by cutting in 0,45 and 90 degree rolling directions on a wire erosion bench according to the ASTM E8 standard. The arithmetic means of the numerical values obtained from the tensile and hardness measurement tests, as well as the standard deviations of the arithmetic means, are shown in Table 1, while the chemical analysis results of the samples are shown in Table 2.

Rubber materials are preferred in the flexforming processes due to their flexibility, high elongation values and resistance to hydraulic pressure. In this study, a $4 \mathrm{~mm}$-thick rubber membrane was used in the flexforming process. To characterize the rubber material used in the experimental study, tensile tests were carried out in three different rolling directions and Shore hardness measurements were taken from three different points on the membrane. Furthermore, 
Table 1. Mechanical properties of test materials

\begin{tabular}{cccccc}
\hline Material & $\begin{array}{c}\text { Tensile Stress at } \\
\text { Yield (MPa) }\end{array}$ & $\begin{array}{c}\text { Maximum Tensile } \\
\text { Stress (MPa) }\end{array}$ & Elongation (\%) & $\begin{array}{c}\text { Young's Modulus } \\
(\mathrm{MPa})\end{array}$ & Hardness (Vickers) \\
\hline $\begin{array}{c}\text { AL 1050-0 } \\
\text { Deviation } \\
\left(\sigma_{\text {AL1050-0 }}\right)\end{array}$ & 100.972 & 121.581 & 6.785 & 37605.611 & 40.066 \\
AL 5754-0 & 1.151 & 2.691 & 1.227 & 153.599 & 0.492 \\
$\begin{array}{c}\text { Deviation } \\
\left(\sigma_{\text {AL5754-0 }}\right)\end{array}$ & 117.497 & 206.443 & 19.255 & 38680.808 & 56.666 \\
\hline
\end{tabular}

Table 2. Chemical composition of test materials ( $w t \%)$

\begin{tabular}{cccccccccc}
\hline Material & $\mathrm{Al}$ & $\mathrm{Fe}$ & $\mathrm{Si}$ & $\mathrm{Zn}$ & $\mathrm{Cu}$ & $\mathrm{W}$ & $\mathrm{Mg}$ & $\mathrm{Pb}$ & $\mathrm{Mn}$ \\
\hline AL 1050-0 & 99.406 & 0.223 & 0.218 & 0.006 & 0.003 & 0.004 & $<$ LOD & $<$ LOD & $<$ LOD \\
AL 5754-0 & 95.537 & 0.344 & 0.306 & 0.059 & 0.080 & $<$ LOD & 3.351 & 0.005 & 0.134 \\
\hline
\end{tabular}

the chemical composition of the membrane was obtained using a spectrometer. Tensile test samples for the rubber membrane material were prepared according to the ASTM D412 standard. The arithmetic means of the numerical values obtained from the tensile and hardness measurement tests, as well as standard deviations of the arithmetic means, are shown in Table 3, while the chemical analysis results of samples are shown in Table 4.

Table 3. Mechanical properties of rubber membrane

\begin{tabular}{cccc}
\hline Material & $\begin{array}{c}\text { Maximum Tensile } \\
\text { stress }(\mathrm{MPa})\end{array}$ & $\begin{array}{c}\text { Elongation } \\
(\%)\end{array}$ & $\begin{array}{c}\text { Hardness } \\
(\text { Shore })\end{array}$ \\
\hline Rubber & 9.112 & 732.816 & 46.166 \\
$\begin{array}{c}\text { Deviation } \\
\left(\sigma_{\text {rubber }}\right)\end{array}$ & 1.503 & 88.591 & 1.545 \\
\hline
\end{tabular}

Table 4. Chemical composition of rubber membrane (wt\%)

\begin{tabular}{ccccc}
\hline Material & $\mathrm{Al}$ & $\mathrm{Si}$ & $\mathrm{Zn}$ & $\mathrm{Zr}$ \\
\hline Rubber & 4.306 & 68.808 & 26.796 & 0.043 \\
\hline
\end{tabular}

\subsection{Experimental study parameters and measurement of springback}

During the determination of the experimental parameters for the flexforming process, the process parameters that have the most effect on springback behavior such as forming pressure, die angle and holding time were considered. In conventional bending experiments, the die angle and holding times were used to compare against the results of the flexforming process. The experimental parameters used in the flexforming process are shown in Table 5, while the experimental parameters for the conventional bending are shown in Table 6.

Equation (1) ${ }^{10}$ was used to calculate the bending loads for AL1050-0 and AL5754-0 sheet metal materials. The calculated bending load values were manually entered into the program for the V-bending experiments using a conventional die.

$$
L=\left(l \cdot t^{2} \cdot k \cdot S\right) / s
$$

where $L$ is press load $(\mathrm{N}), l$ is length of bend (mm), $t$ is sheet metal thickness ( $\mathrm{mm}), \mathrm{k}$ is a die-opening factor, $S$ is tensile strength of the sheet metal $\left(\mathrm{N} / \mathrm{mm}^{2}\right)$, and $s$ is the width of the die opening $(\mathrm{mm})$.

Table 5. Experimental study parameters of V-bending by flexforming process

\begin{tabular}{lc}
\hline Experiment Parameters & Parameter Values \\
\hline Bending pressure (MPa) & 10,12 and 14.4 \\
Bending die angle (Degree) & $15,30,45,60,75,90$ \\
Holding time (sec.) & $0,5,10$ \\
Rubber membrane thickness (mm) & 4 \\
\hline
\end{tabular}

Table 6. Experimental study parameters of V-bending by conventional die bending

\begin{tabular}{lc}
\hline Experiment Parameters & Parameter Values \\
\hline Bending die angle (Degree) & $15,30,45,60,75,90$ \\
Holding time (sec.) & $0,5,10$ \\
Punch radius (mm) & 4 \\
\hline
\end{tabular}

After the experimental study, the measurement of the springback for V-bended sheet metal materials was performed using a Coordinate Measuring Machine (CMM). Before measurements, test materials were prepared by bonding them onto a flat sheet metal material with an elastic adhesive. Plane measurements were obtained by touching each bent surface at four points with the probe of the CMM. Then, the angle between the planes was measured. The springback angle was found by subtracting the measured angle from the bent angle. A schematic view and measurement of springback in the CMM are shown in Figure 5. 


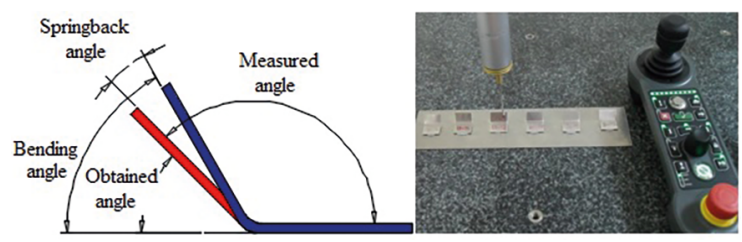

Figure 5. The schematic view of springback and measurement in the CMM

\section{Results}

The results obtained from the experimental work was evaluated and interpreted by considering the effects of die angle, holding time, bending pressure and the mechanical properties of materials with springback.

\subsection{Effect of die angle on springback}

During the forming process for bending, sheet metal materials plastically deform. During deformation, compression stresses occur on the inner surface of the sheet metal where the punch is in contact with the sheet metal, and tensile stress is formed on the outer surface of the sheet metal. When the punch moves upwards after the completion of the deformation process, compression and tensile stress move in opposite directions until they balance each other out. Deformation is complete when the balance between stresses is achieved. The amount of springback in sheet metal materials is determined by the magnitude of the bending moment distribution. This is because the bending moment at a given cross-section is a function of the internal stress distribution generated by forming ${ }^{11}$. In the bending processes, the bending moment increases with increasing die angle, which in turn also increases the stresses generated during bending. High amounts of stress increases springback in sheet metal materials. Similarly, it was observed in the experimental studies that springback increased with increasing die angle in V-bending operations with both the conventional and flexforming methods. In V-bending experiments with a conventional die, the highest springback angle was obtained at a 90 degree die angle and 0 seconds holding time. The highest springback angle values obtained for these experimental parameters were 3.583 degree and 3.777 degree for AL1050-0 and AL5754-0 sheet metal materials, respectively.

Uniform hydraulic pressure is applied to the sheet metal material in bending operations using the flexforming process. With the applied pressure, stress is homogeneously distributed over the sheet metal material. However, in the conventional bending process, stresses concentrate on the edge of the punch. In this study, because an equal and controlled stress distribution was achieved on the sheet metal in the flexforming process, a smaller amount of springback was observed in bending operations. Moreover, because the bending moment and stress density increased with increasing die angle, springback also increased with respect to the amount of increase in the die angle. The highest springback angle in the flexforming process was obtained at a 90 degree die angle, 0 seconds holding time and a $10 \mathrm{MPa}$ die pressure. The highest springback angle values obtained for these experimental parameters were 1.413 degree and 2.194 degree for AL1050-0 and AL5754-0 sheet metal materials, respectively. The changes in the springback values - obtained from forming operations through conventional and flexforming processes - with respect to die angle and holding time are shown in Figure 6 and 7 for AL1050-0 and AL5754-0 sheet metal materials, respectively.

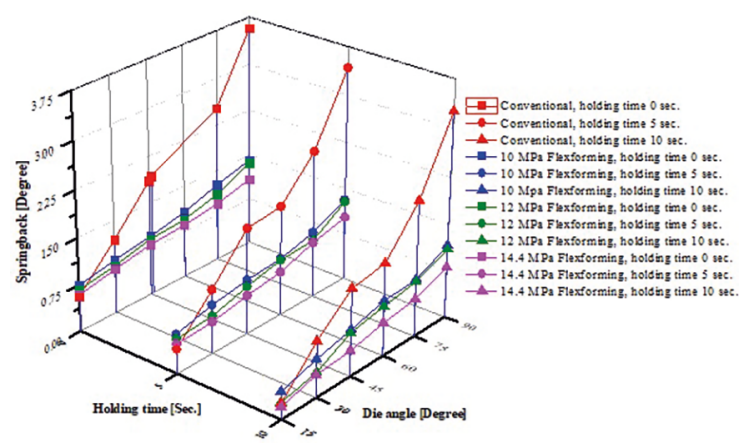

Figure 6. The effects of die angle and holding time on springback for AL 1050-0 sheet metal

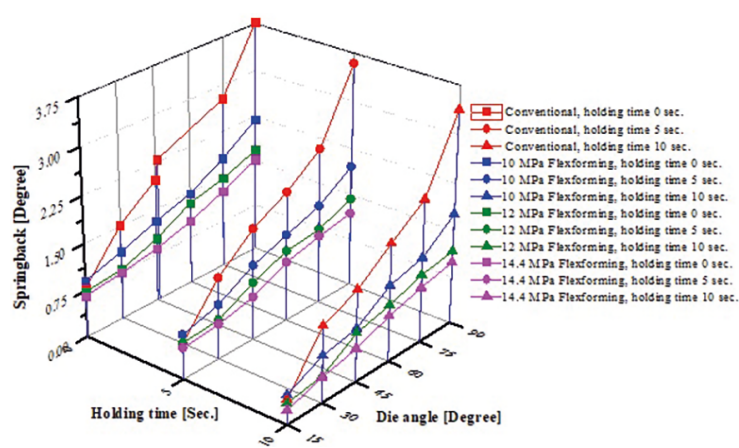

Figure 7. The effects of die angle and holding time on springback for AL 5754-0 sheet metal

When comparing V-bending operations using the conventional and flexforming processes with respect to springback angle, it was observed that the springback angle obtained in the flexforming process was smaller than that obtained in the conventional bending method. It was determined that decreases were $60.57 \%$ (from 3.583 degree to 1.413 degree) and $41.92 \%$ (from 3.777 degree to 2.194 degree) for AL1050-0 and AL5754-0 sheet metal materials, respectively.

\subsection{Effects of bending pressure and holding time on springback}

Forming load and holding time are some of the most important parameters affecting springback. In conventional V-bending operations, it is observed that springback decreases 
with increased bending load applied to the bending zone ${ }^{12}$. Furthermore, it was determined that in conventional bending operations a decrease in friction increased springback ${ }^{13}$. To observe the effect of the forming load on springback, three different forming pressures $(10,12$ and $14.4 \mathrm{MPa})$ were used in the flexforming process. Increases in the forming pressure caused an increase in friction due to the increase in the forming load and the equal pressure applied to the surface of the sheet metal. It was observed after the experimental study that a $10 \%$ increase in the forming pressure decreased the springback angle by 0.08 degree and 0.23 degree for AL1050-0 and AL5754-0 sheet metal materials, respectively.

In bending operations, an increase in the holding time is a key process parameter that has a significant effect in decreasing springback. During the holding time, the shape of the formed part is limited, and internal stresses are relieved when bending. The increase in internal stresses decreases elastic strains in the bending zone and increases permanent (plastic) strains. This phenomenon causes a decrease in the springback caused by elastic recoveries ${ }^{14}$. It was seen that a five-second increase in the holding time decreased the springback angle by 0.14 degree and 0.19 degree for AL1050-0 and AL5754-0 sheet metal materials, respectively. The changes in the springback angle, with respect to holding time and bending pressure, are graphically shown in Figure 8 and 9 for AL1050-0 and AL5754-0 sheet metal materials, respectively.

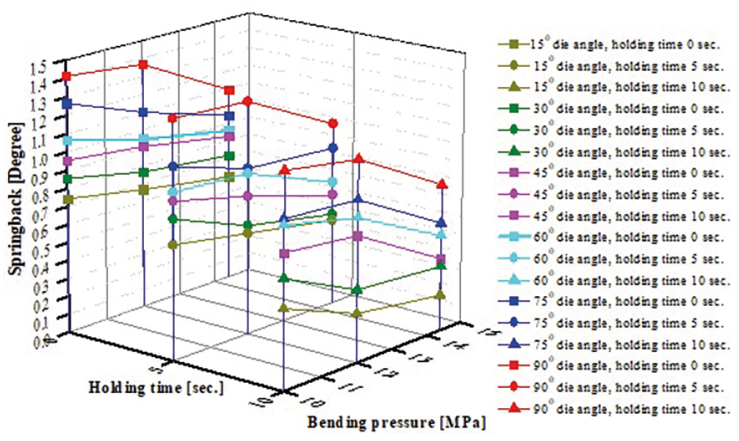

Figure 8. The effects of holding time and bending pressure on springback for AL 1050-0 sheet metal

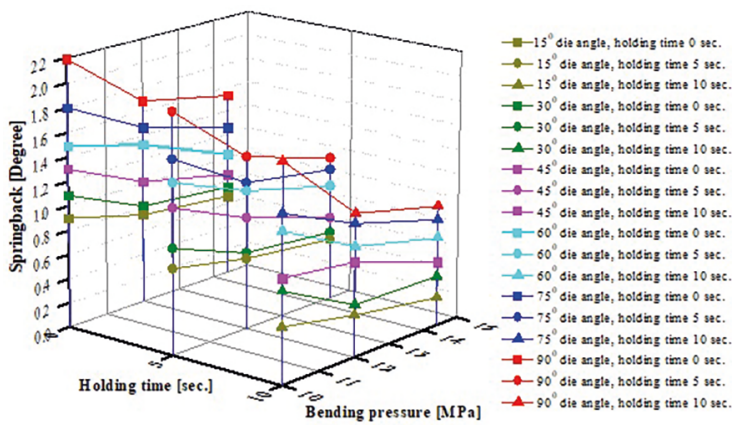

Figure 9. The effects of holding time and bending pressure on springback for AL 5754-0 sheet metal

\subsection{Effects of material properties on springback}

After the metal forming operation, the springback phenomena depends on the material properties such as the plastic strain ratio, yield strength, the strain-hardening exponent and the Bauschinger effect. The sheet metals with high strength always show greater springback in comparison to mild sheet metals. Also, the springback angle increases with increasing strength, yield stress and strain hardening ${ }^{15-17}$. In the scope of this study, the effects of yield stress and the hardness properties of the test materials on springback were considered. For both types of forming operations, it was determined that the AL5754-0 sheet metal material having a higher yield stress and hardness values - had more springback than the AL1050-0 sheet metal material. For the same experimental parameters, the highest springback angle in conventional bending experiments was 3.583 degree and 3.777 degree for AL1050-0 and AL5754-0 sheet metal materials, respectively. On the other hand, the highest springback angle in the flexforming process was 1.413 degree and 2.194 degree for AL1050-0 and AL5754-0 sheet metal materials, respectively.

\subsection{Surface forming defects on parts resulting from the $V$ bending process}

One of the defects observed in parts formed by bending is a surface forming defect. These occur on the part during forming. If the formed part is to be used for an application that needs to be esthetically pleasing, surface treatments should be performed to eliminate surface forming defects. However, additional surface treatments increase the cost of the part. Stamping/coining occurs in the sheet metal material placed between the die and punch when forming uses the conventional bending techniques. At the onset of the bending operation with a conventional die, the curvilinearity of the sheet metal material is smaller than that of the punch tip radius. With the progress of bending, the punch load increases and the forming process continues until the curvilinearity of the punch tip radius becomes equal to that of the sheet metal material. At the endpoints of the punch tip radius, the sheet metal material is squeezed until equality is achieved between the curvilinearity of the punch tip radius and the sheet metal material. The formation of forming defects is apparently seen due to squeezing of the sheet metal material at contact points at the endpoints of the punch radius ${ }^{18}$. In experimental studies, formation of surface defects was observed on sheet metal materials due to the squeezing effect in bending operations with a conventional die. On the other hand, in the flexforming process, a rubber membrane forms the sheet metal materials in the die through uniform pressure, without creating any surface defects. In the flexforming process, unlike the forming process with a conventional die, the sheet metal material is not squeezed between the die and the punch because a rubber membrane 
is used instead of a rigid punch. This phenomenon eliminates the formation of surface defects on the formed surfaces of the sheet metal material. Surface qualities of the formed parts are shown in Figure 10.
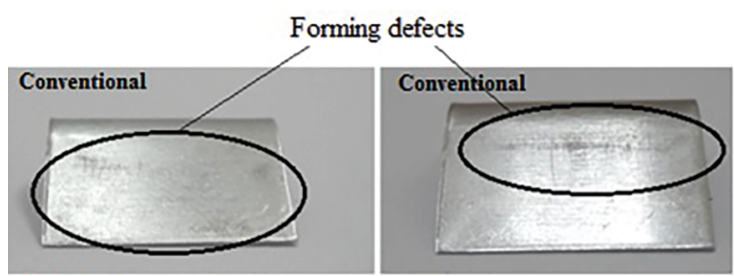

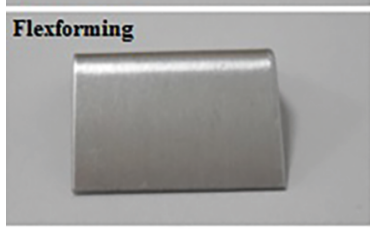

a

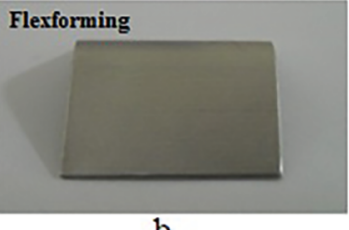

b
Figure 10. Surface qualities of the formed parts a) AL 1050-0 and b) AL 5754-0

\section{Prediction of Springback by Fuzzy Logic}

A fuzzy logic system - which is an extension of conventional logic where a concept is defined as true or false - is a logic system that considers many cases between true and false ${ }^{19}$. A fuzzy logic system is built with fuzzy logic rules that operate between input and output variables. In the system, the "fuzzification" unit converts numerical values in the input unit into fuzzy variables. A fuzzy inference process is set into the rules table that includes linguistic control rules. The outcomes of this rules table are linguistic variables. The "defuzzification" unit in the output unit converts these available linguistic variables back into numerical values ${ }^{20}$. The values obtained are between 0 and 1 in the fuzzy logic system. A fuzzy logic system commonly used in various disciplines was used in this study to estimate springback angles with respect to unexecuted break-test parameters. The first step in defining the fuzzy system, forming pressure (10, 12 , and $14.4 \mathrm{MPa})$, die angle $(15,30,45,75$, and 90 degree $)$ and holding time $(0,5$, and 10 seconds) were defined as the input variables, while springback was defined as the output variable. During the step for definition of variables, minimum and maximum values of each variable, and the number of variables were defined for the fuzzy system. The Compute MBF method was selected as the fuzzification method, and each variable value was transformed into linguistic variables during the fuzzification step. Linguistic variables were defined as "very low", "low", "medium", "high" and "very high" for the die angle, while they were defined as "low", "medium", and "high" for both forming pressure and holding time. A rule block was constructed consisting of 90 rules and 16 membership functions. The maximum membership method (Center of Maximum - CoM) was used as the Defuzzification
Method. With the help of defuzzification, exact output values were obtained by transforming each linguistic variable into numerical variables between 0 and 1 . The definition of the fuzzy logic system is shown in Figure 11.

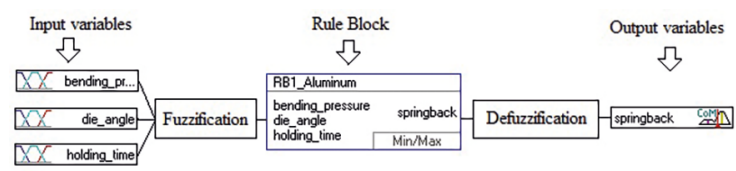

Figure 11. The definition of the fuzzy logic system

To determine the distribution of the deviation between the springback predicted by the fuzzy logic system and the experimental study results, experiments with a 60 degree die angle were not included in the system during the definition step for the fuzzy logic system. Springback results obtained from the experiments with a 60 degree die angle were compared with those obtained from the fuzzy logic system. The accuracy value was calculated to be $93 \%$ for both AL1050-0 and AL5754-0 sheet metal materials. Fuzzy logic estimations and experimental study results of AL1050-0 and AL5754-0 sheet metal materials are shown in Figure 12.

a
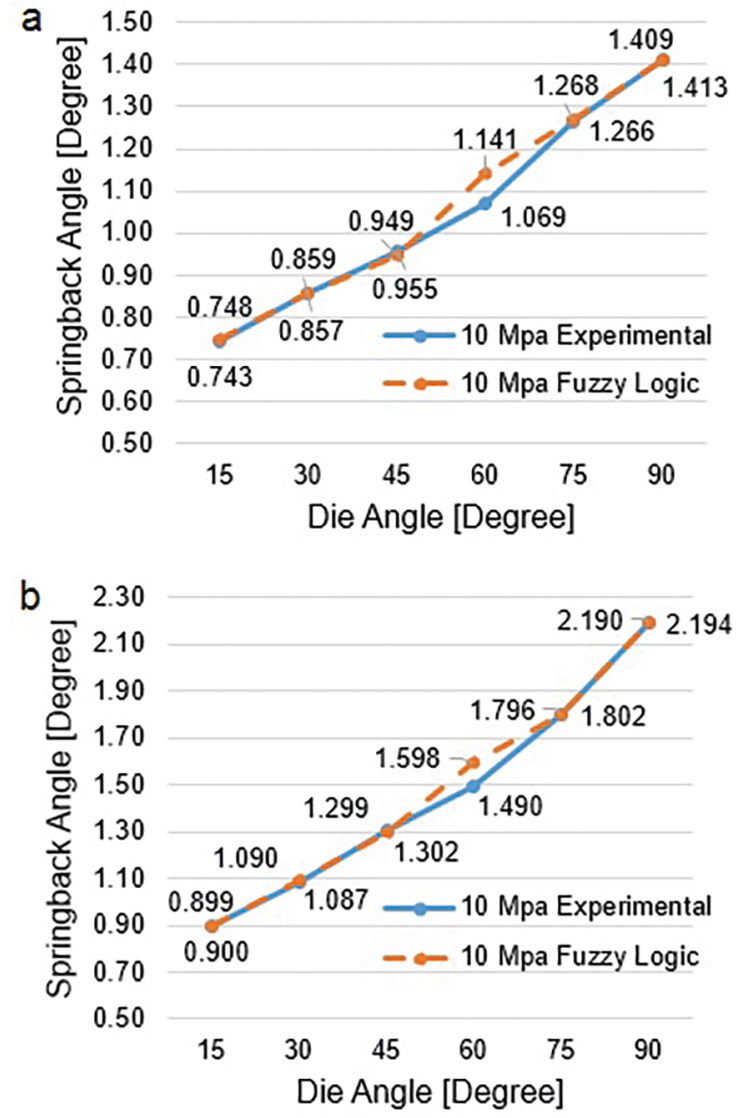

Figure 12. The experimental study results and fuzzy logic model predictions a) AL 1050-0 b) AL 5754-0 
Because the fuzzy logic system could estimate the springback angle with a higher accuracy, springback angles were predicted by the fuzzy logic system for unexecuted break-test parameters. Springback predictions done by using the fuzzy logic system according to unexecuted break-test parameters are shown in Figure 13, for both sheet metal materials.

a
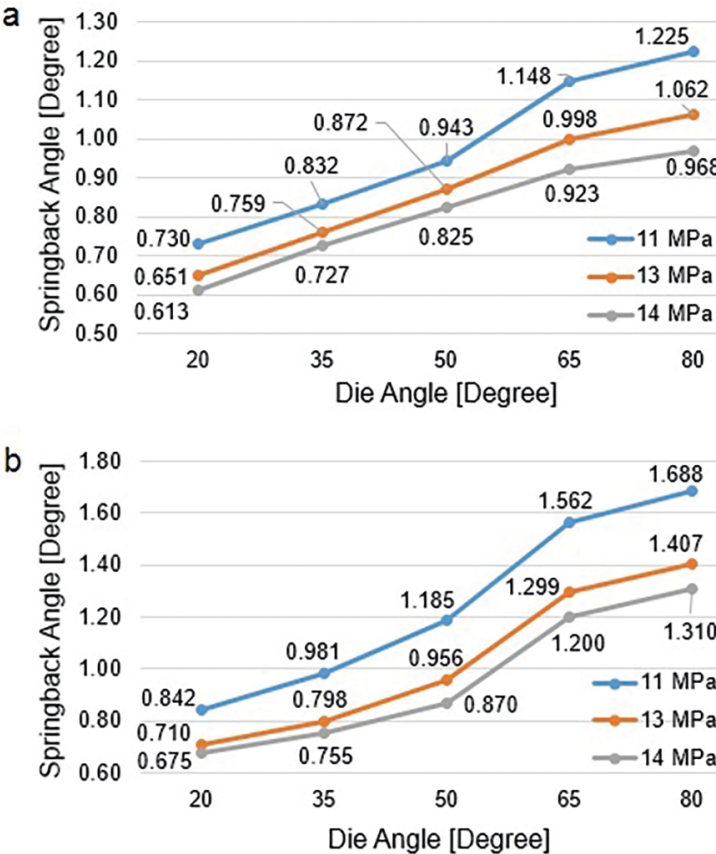

Figure 13. The predictions of springback by the fuzzy logic system a) AL 1050-0 and b) AL 5754-0

\section{Conclusions}

This study experimentally investigated the process parameters affecting springback in V-bending of AL1050-0 and AL5754-0 sheet metal materials using the flexforming process. It was determined that die angle and holding time significantly influenced the springback. A 15 degree increase in the die angle increased the springback angles by 0.12 degree and 0.23 degree for AL1050-0 and AL5754-0 sheet metal materials, respectively. Furthermore, it was found that a five-second increase in the holding time decreased the springback angle 0.14 degree and 0.19 degree for AL1050-0 and AL5754-0 sheet metal materials, respectively. It was determined that the springback angle in the parts bent by the flexforming process were $60.57 \%$ and $41.92 \%$ lower than that in the parts bent by conventional bending for AL1050-0 and AL5754-0 sheet metal materials, respectively. According to unexecuted break-test parameters, springback angles could be predicted by using the fuzzy logic system with $93 \%$ accuracy for both material types. In the flexforming process, surface forming defects were not observed on the parts formed due to the homogeneous application of forming pressure on the part and the use of a rubber membrane material during bending. Moreover, when a thin membrane was used in the flexforming process, it was observed that fluid pressure was more efficiently transferred to the part, and the thin membrane allowed the pressure to form tight profiles more easily, which makes a positive contribution to the process.

\section{Acknowledgements}

This work was supported by the Gazi University Scientific Research Department with 07/2013-09 project number.

\section{References}

1. Hatipoğlu HA, Polat N, Köksal A, Tekkaya AE. Modeling Flexforming (Fluid Cell Forming) Process with Finite Element Method. Key Engineering Materials. 2007;344:469-476.

2. Koç M. Hydroforming for Advanced Manufacturing. Cambridge: Woodhead Publishing; 2008.

3. Schilp H, Suh J, Hoffmann H. Reduction of springback using simultaneous stretch-bending processes. International Journal of Material Forming. 2012;5(2):175-180.

4. Chatti S, Hermi N. The effect of non-linear recovery on springback prediction. Computers \&. Structures. 2011;89(1314):1367-1377.

5. Naceur H, Guo YQ, Ben-Elechi S. Response surface methodology for design of sheet forming parameters to control springback effects. Computers \&. Structures. 2006;84(26-27):1651-1663.

6. Kulkarni P, Prabhakar S. Influence of the Effect of Strain Rates on Springback in Aluminum 2024 (ISO AlCu $\mathrm{Mg}_{1}$ ). In: Proceedings of $4^{\text {th }}$ European LS-DYNA Users Conference; 2003 May 22-23; Ulm, Germany.

7. Palaniswamy H, Ngaile G, Altan T. Optimization of blank dimensions to reduce springback in the flexforming process. Journal of Materials Processing Technology. 2004;146(1):2834.

8. Hatipoğlu HA, Polat N, Köksal A. A Methodology to Determine the Friction Coefficient in Flexforming (Fluidcell Forming) Process. AIP Conference Proceedings. 2010;1252(1):278.

9. Karaağaç I. The Experimental Investigation of Springback in V-Bending Using the Flexforming Process. Arabian Journal for Science and Engineering. 2017;42(5):1853-1864.

10. ASM International. International Handbook. Volume 14: Forming and Forging. Materials Park: ASM International; 1993.

11. Firat M, Kaftanoglu B, Eser O. Sheet metal forming analyses with an emphasis on the springback deformation. Journal of Materials Processing Technology. 2008;196(1-3):135-148.

12. Marcondes PVP, dos Santos RA, Haus SA. The coining force influence on springback in TRIP800 steel V and L-bending processes. Journal of the Brazilian Society of Mechanical Sciences and Engineering. 2016;38(2):455-463. 
13. Srinivasan R, Vasudevan D, Padmanabhan P. Influence of friction parameters on springback and bend force in air bending of electrogalvanised steel sheet: an experimental study. Journal of the Brazilian Society of Mechanical Sciences and Engineering. 2014;36(2):371-376.

14. Zong Y, Liu P, Guo B, Shan D. Springback evaluation in hot $\mathrm{v}$-bending of Ti-6Al-4V alloy sheets. The International Journal of Advanced Manufacturing Technology. 2014;76(1-4):577-585.

15. Ouakdi EH, Louahdi R, Khirani D, Tabourot L. Evaluation of springback under the effect of holding force and die radius in a stretch bending test. Materials \& Design. 2012;35:106-112.
16. Esat V, Darendeliler H, Gokler MI. Finite element analysis of springback in bending of aluminium sheets. Materials \& Design. 2002;23(2):223-229.

17. Panthi SK, Ramakrishnan N, Ahmed M, Singh SS, Goel MD. Finite Element Analysis of sheet metal bending process to predict the springback. Materials \& Design. 2010;31(2):657-662.

18. Marciniak Z, Duncan JL, Hu SJ. Mechanics of Sheet Metal Forming. Oxford: Butterworth/Heinemann; 2002.

19. Yager RR, Zadeh LA, eds. An Introduction to Fuzzy Logic Applications in Intelligent Systems. New York: Springer; 1992.

20. Çavuşoğlu $\mathrm{O}$, Gurun H. Investigation and fuzzy logic prediction of the effects of clearance on the banking process of CuZn30 sheet metal. Kovové Materiály. 2016;54(2):125-131. 